\title{
Teaching Material Model of Reading Subject in the Form of Contextual Chinese Literary and Cultural Texts
}

\author{
$1^{\text {st }}$ Febi Nur Biduri ${ }^{1}, 2^{\text {nd }}$ Yumna Rasyid, $3^{\text {rd }}$ Emzir \\ feibinur@gmail.com¹, Yumna.rasyid@unj.ac.id ${ }^{2}$,Emzir.unj@gmail.com ${ }^{3}$ \\ Pendidikan Bahasa Jakarta State University, Indonesia ${ }^{123}$
}

\begin{abstract}
The cultural and literary knowledge that has been studied in the reading class of the Chinese Language and Culture Study Program at Darma Persada University is not yet maximal and not yet in accordance with the students' needs. Prompted by the issue, this research aims to develop a learning product that is in line with the needs of the study program. The procedure in this study employs Borg and Gall's theory. The data collection is done by distributing a questionnaire, observation, discussion, interview, and test. The validity and reliability tests for the teaching material model employ peer assessment, expert assessment, and testing and questionnaire distribution to the students. The effectiveness test is carried out using a paired sample t-test to compare the data before and after the learning process. The $\mathrm{T}$ count is (4.060) greater than the T-table (2.101). Thus, it can be concluded that the developed teaching material model is very feasible and can be used for Reading V course in the Chinese Language and Culture study program.
\end{abstract}

Keywords: Model, Chinese literary and cultural work, contextual learning, students's skill improvement 


\section{Introduction}

The lessons about culture and literature in Reading V course at Chinese Language and Culture Study Program of Darma Persada University have not been maximally provided and in accordance with the needs of the students and the study program. Therefore, to adjust to the needs, it is necessary to make the teaching materials contextually learned.

The use of contextual approach is chosen in developing the teaching materials because although the approach is used in the Reading V course, it has not been maximally employed in the teaching and learning process. This is identified from the results of interviews with the students who argue that the learning process is just reading and translating texts.

Johnson (2008)[1] states that contextual learning and teaching connects academic lessons with the real-life context that students encounter. By linking the two they can comprehend the meaning within the task. In addition, such a learning is expected to improve their critical thinking skills.

The teaching material model of Reading V based on the contextual texts of Chinese language literature comprises various Chinese literary texts of legend, myth, and folklore. The Chinese cultural elements in the texts will be the theme of Chinese people in China, Chinese building architecture, traditional Chinese medicine, and eating and drinking habits of the Chinese people.

Those teaching materials are used in Reading V course which becomes one of the compulsory subjects in Chinese Language and Culture Study Program, Faculty of Literature, Darma Persada University, Jakarta. This course discusses the process of Reading $\mathrm{V}$ as well as the understanding of Chinese texts. It is tiered and conditional consisting of Reading I to Reading VI.

The teaching materials development model proposed in this study refers to Brown's concept. He proposes a three-stage development procedure (Brown, 1995)[2] combined with the Borg's and Gall's (1983)[3] model comprising ten steps.

The materials according to the National Center for Competency-Based Training stated by Prastowo (2012) are all forms of materials used to assist the teachers or instructors in carrying out the learning process in the classroom. It can be written or unwritten materials whereas according to Nunan's concept of teaching materials development the process of selecting, adapting, and creating the teaching materials are based on a particular framework of reference (1991).

This learning model encouraged the students to obtain knowledge from experience and was in accordance with the existing learning environment. They became more enthusiastic when learning the literature and culture and raised their critical thinking within the contextual learning.

Teaching involves the students actively in the teaching and learning activities according to one of the contextual principles, commonly called an inquiry. The effectiveness of contextual literary and cultural contexts is not only proven in this study. There were also several other universities that have applied literary and cultural themes or one of the concepts of contextual learning in the classrooms. First, research was conducted by Lee (2014) [4]about inquiry-based language teaching. It aimed to provide autonomous inquiry-based teaching within the framework of the cognitive approach so that it can be easily integrated into L2 classes that are tailored to the needs of L2 education.

The second research was conducted by Xiao about integrated English in China through a CLIL model. It aimed to shift the learning model from reading to doing activities to doing the opposite and utilizing the target language as the language medium to learn and emphasize the integrated approach in the learning.

The third research conducted by Jakob about the power of context in teaching and learning culture. It aimed to change the teacher's view on things such as culture or teaching methods as the starting point for their teaching process. It only focused on the creation of embedded knowledge and values that can direct and guide the cultural teaching process.

However, there are some differences and similarities between the previous research and the present research. It is based on the effectiveness test that has been proven to promote academic reading skills. The similarity lies on the same focus on the literary and cultural aspects which are contextual. The three students had an independent and critical attitude toward the new knowledge given. The last was the teacher used the contextual concept of changing their views on the use of the teaching materials. 
Meanwhile, this is the first study whose research target is the Chinese language students who are not Chinese descendants. The literary and cultural themes are contextual in the teaching materials as well as the exercises. Those three teaching materials were adjusted according to the needs and desires of UNSADA students. The last is in addition to reading classes, the teaching materials produced from this study can be applied in other learning settings because they have broad enough themes, which might encourage students' autonomy and critical thinking while using this book.

Prompted by the aforementioned points, this study aims to address the question of (1) how the model of teaching materials of Chinese Reading V with a contextual approach is developed and (2) how the literary and cultural elements in the form of story in developing the Reading $\mathrm{V}$ skills are introduced.

\section{Methode}

This research employs research and development method proposed by Borg and Gall using qualitative analysis and effectiveness test. The effectiveness test is conducted through preexperimental research involving only one experimental class for pre-test and post-test group designs. The data used are from pre-experiment and post-experiment. The effectiveness test is conducted by using the data from the Reading V course. Eighteen (18) students are involved to be the participants.

The procedure follows several steps of research and development method as follows. First, a preliminary research consists of requirement analysis and teaching materials analysis previously used. Needs analysis consists of the discovery of activities in the field of students' needs on the theme of learning materials in Reading $\mathrm{V}$ course and about the learning theory tailored to the teaching materials. Second, the planning stage involves the literature review and the supporting concepts related to the needs of teaching materials. Third, designing stage aims to analyze the theoretical framework and empirical data. A small-group test is conducted by organizing sample model testing, model socialization, and teaching material revision. Fourth, revision 1 involves model revision based on the questionnaire results from experts and practitioners. Fifth, a large group test is the determination of sample measurement, measurement of teaching materials after implementation. Sixth, revision 2 involves the assessment of the shortage of teaching materials, follow-up planning and model revision. Seventh, effectiveness test involves the use of the teaching material model directly in the classroom learning. Eighth, the final model as the result of the implementation is the model recommended to be used in the Reading V course in the form of texts about the Chinese literature and culture contextually. Meanwhile, the data analysis process is elaborated in Table 1 as follow.

Table 1. Data Analysis

\begin{tabular}{|l|l|c|}
\hline \multicolumn{1}{|c|}{ Data } & \multicolumn{1}{|c|}{ Data Collection Instruments } & Data Analysis Techniques \\
\hline $\begin{array}{l}\text { Needs analysis (lecturer, } \\
\text { department staff, and students) }\end{array}$ & Survey and interview & Descriptive (Qualitative) \\
\hline Expert test & Questionnaire & Descriptive (Qualitative) \\
\hline $\begin{array}{l}\text { Field trial as the validation and } \\
\text { feedback from the users after } \\
\text { revision }\end{array}$ & Questionnaire & Descriptive (Qualitative) \\
\hline $\begin{array}{l}\text { Operational field test to obtain } \\
\text { the product effectiveness }\end{array}$ & Pre Test and Post Test & T-test (Quantitative) \\
\hline
\end{tabular}




\section{Findings and Discussion}

\section{The Results of Needs Analysis}

The needs analysis in this research was conducted to find out the needs of Reading V teaching materials for the students and the teachers. Munby (1978)[5] in Communicative Syllabus Design says that designing a program model that suits the needs of the learners is important in foreign language learning.

Furthermore, Jordan (2003)[6] states that each individual learner has distinctive needs. Thus, through needs analysis, the teachers and the program organizer can find the average ability and needs of the group of learners. Then it aims to make the teaching materials in accordance with the demands of the competencies that must be mastered by them.

Hutchinson and Waters (1987)[7] in Nation and Macalister divided needs into two types, namely target needs and learning needs. This research focused on the target needs consisting of three elements, namely needs, expectations, and weaknesses.

The interview and questionnaire data were collected from the students, lecturers, and experts in the field of needs analysis. It suggested that the obtained Chinese literature and culture resulted in the reasons why the Chinese literary and cultural texts were needed to be included in the teaching materials for Reading V subject. Although the lecturers' and students' knowledge about literary texts and Chinese culture varied, it was not sufficiently good in quality and capacity. The students tended to only know the title of the story. The analysis of the weaknesses of the previous learning materials resulted in the fact that the students were not able to read and answer the questions related to the title of the story they actually know.

Based on the needs analysis, it was also known that the contextual learning is needed because its concept helps lecturers associate the materials with the real-world situation of the students and encourage them to make connections between their knowledge and the application in their daily lives. The contextual approach can help students understand the meaning of the teaching materials by linking it to the context of their daily lives so that they have the knowledge or skills to construct their own understanding.

This is also reinforced by the results of Firdaus's research (2016)[8] with the title Development of thematic contextual textbooks. It stated that in contextual learning the students gain knowledge and skills from the results of learning by themselves (inquiry), not the results of remembering a set of facts. From the findings regarding the needs of the students and the teachers, there is also the expectations analysis that the students want about the reading materials. They want to have linguistic and grammar materials as well as Chinese idioms with various literary and cultural stories.

The Results of Learning Condition Analysis and Current Teaching Materials

Based on the analysis of learning condition and teaching materials, it can be said that the learning condition of Reading $\mathrm{V}$ course must be supported with syllabus and teaching materials that are in accordance with current needs. The available syllabus and materials have not integrated a contextual approach and have not yet accommodated the students' literary and cultural competencies. Thus, the Unsada students who have enrolled in the course do not know enough literary and cultural knowledge. This is because the syllabus and the available materials have not been aligned with the students' interests in literature and culture.

In addition, the teachers use only one book for each meeting. They then prepare the learning model first without any uniformity. It makes the teaching become less effective.

Based on the analysis, it can be concluded that Unsada needs syllabus and teaching materials with literary and cultural themes under the contextual approach. This equality will facilitate the validation of competence and evaluation. The results of the evaluation of students who have the ability to understand literature and culture will be in accordance with the needs of the university and facilitate the recognition from the native people because the descriptor of competence in Reading V course with literary and cultural standards has been clear and in accordance with the department demands. 


\section{The Framework of the Developed Learning Model}

The textbook has three components: (1) reading text, (2) practice, and (3) test review after three themes. The teacher manuals are structured to guide the lecturers in teaching the materials in the textbooks. The materials consist of literary and cultural themes according to the results of the needs identification, credit points, and exercise model adjusted to the contextual approach. The image below is a figure of the model in Reading $\mathrm{V}$ course in the form of contextual literary and cultural texts that are tested.

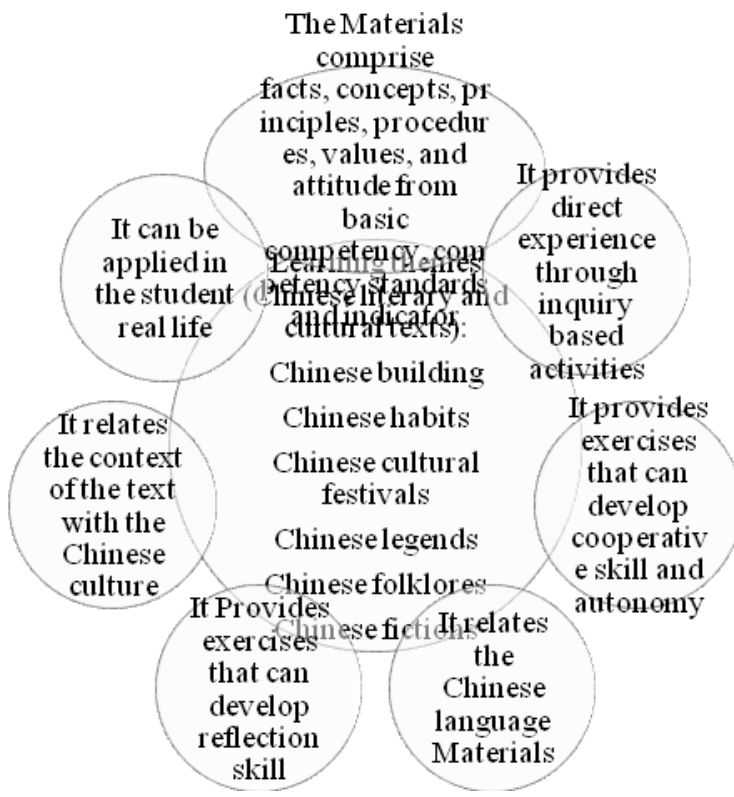

Figure 1. The framework of the teaching material model development

\section{Feasibility and Implementation of The Model}

The theoretical feasibility test is conducted on the syllabus and the model of the compiled teaching materials. Based on the experts' opinions, all the required dimensions of the syllabus have met the category. The syllabus has fulfilled the dimensions which include (a) the framework of reference of the syllabus, (b) the competency standard (SK), the basic competence (KD) and the indicator, (c) the theme accuracy, (d) the reading skill, (e) the linguistic material, (f) the design and organization of the materials, $(\mathrm{g})$ the teaching process under contextual approach and (i) the allocated time for the SK / KD.

For the draft III teaching material model, the assessment is conducted by two experts consisting of one Chinese language teaching expert and one Chinese literary and cultural expert. Both experts are looking at the three teaching materials that have been developed and then give their own opinions by filling the feasibility questionnaire.

The questionnaire consists of 20 items with four choices, i.e. $1=$ Strongly disagree, $2=$ disagree, 3 = agree and $4=$ strongly agree. The average score is as much 3.7 with 'very feasible' category. In particular, the language content and literary and cultural content dimensions get high marks. In general, all dimensions in question are judged to be highly qualified by the experts. The dimensions are (a) refers to the development of Reading $\mathrm{V}$ teaching materials, (b) objectives and approaches, (c) design and organization of the teaching materials, (d) language skill content, (e) literary and cultural content, (g) themes / and (h) methodology. 
Based on the above explanation, it can be concluded that the syllabus and model of the teaching materials theoretically are categorized 'very feasible'. This is reinforced by the empirical feasibility which is illustrated from the data of the students' learning outcomes after the model is tested widely.

The Perceptions of Test Users about the Developed Teaching Materials

To test the users' perceptions about the developed materials, it firstly analyzes the students' perceptions as the users. There are 20 items with four choices $1=$ Strongly disagree, $2=$ disagree, $3=$ agree and $4=$ strongly agree. The average score is in the 'feasible' category with the highest score on literary and cultural materials. Figure 2. depicts the average score of the students' perceptions of the draft IV of the teaching material model.

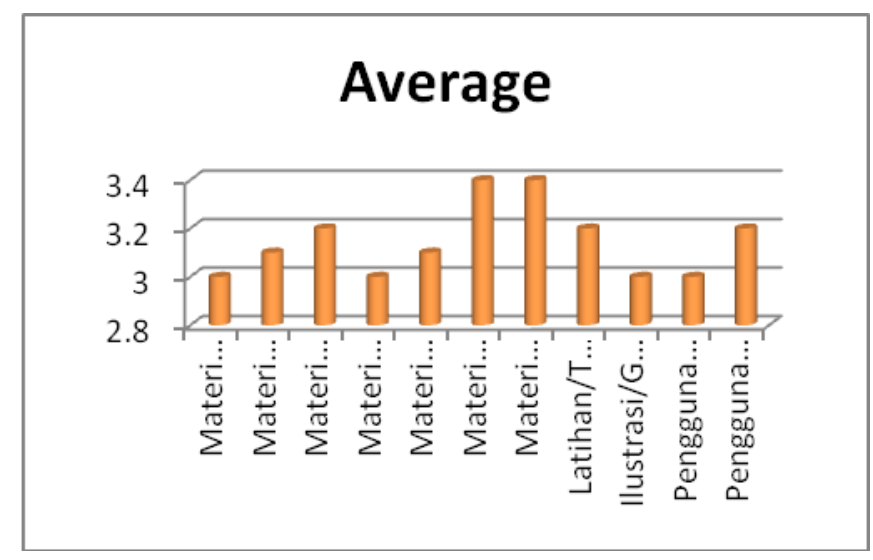

Figure 2. The scores of students' perceptions on the teaching material model in Large-scale trial

Furthermore, the lecturers' perceptions were also tested by using a 20 -item questionnaire with four choices 1 = Strongly disagree, 2 = disagree, $3=$ agree and $4=$ strongly agree. It was concluded that the model of the teaching materials about the contextualized literary and cultural texts was quantitatively categorized as feasible to use. This can be seen on the following table.

Table 2. Lecturers' Perceptions on the Model of the Teaching Materials

\begin{tabular}{|l|l|l|l|l|}
\hline No. & Aspect & $\begin{array}{l}\text { The average score of } \\
\text { the Average score } \\
\text { perceptions }\end{array}$ & Category \\
\hline 1 & $\begin{array}{l}\text { Reference to the preparation of } \\
\text { the teaching materials }\end{array}$ & 3 & 3 & Feasible \\
\hline 2 & Purpose and approach & 3 & 3 & Feasible \\
\hline 3 & Design and organization & 3 & 3 & Feasible \\
\hline 4 & Language skills content & 3 & 3 & Feasible \\
\hline 5 & Linguistic content & 3 & 3 & Feasible \\
\hline 6 & Literary and cultural content & 3 & 3 & Feasible \\
\hline 7 & Theme/topic & 3 & 3 & Feasible \\
\hline 8 & Methodology & 3 & 3 & Feasible \\
\hline & Average & 3 & 3 & Feasible \\
\hline
\end{tabular}




\section{The Effectiveness of the Developed Teaching Material Model}

To test the effectiveness of the model, the researchers conduct an experimental research by employing pre-experimental design. Therefore, it is only implemented in one Reading Class V at the Unsada to 18 students.

The data from the final-semester exam (UAS) are used as the post-test and at the beginning of the learning process, they also undergo a pretest. The results of pre- and post-tests are tested by using a T-test. The teaching materials used in the experimental class are taken from the developed model of the draft V. The lecturers use the teachers' book as a guide before teaching. In the learning process, the students use the textbooks. Each task is done in a notebook.

The lowest score in the experimental class is 60 and the highest one is 100 with an average value of 87.78. Meanwhile, the lowest pre-test score is 60 and the highest one is 100 with an average of 74.50. Both samples come from the normal distribution. The next test is a twoaveraging difference test to test the null hypothesis. It is concluded that there is no average difference between pre-test and post-test. The test used is a t-test.

The developed model of teaching materials has also been through a legibility test. Chall and Dale (1995) stated, "Educators have used the term readability to describe all the text features that influence how people read and understand a book." It means that educators must use the possibility of text content that might later affect the readers to read and understand the contents of the book. To test the legibility of a book, Hillcerst's (2008) mentions five steps, namely survey, purpose, assessment material, evaluation, and product implementation in a test.

Readability test was carried out by giving a questionnaire to one lecturer of Reading V, two colleagues, and one expert in teaching Chinese language. The text in the final model of Reading material V has fulfilled the 'eligible' category with a score of $80 \%$ feasible, so that the advice given by the assessor was more focused on the sequence of themes in which the cultural theme goes first, followed by the literary theme. It is because the literary theme is considered more difficult. The advice was also focused on the layout out of the printed results.

\section{Conclusion}

This conclusion is based on the process of model development and evaluation results on the model as follows. The students' needs to learn reading Chinese literary and cultural texts in the Faculty of Literature, Chinese Literature Study Program, University of Darma Persada are based on the components of needs and desires. The students consider the importance of Chinese literary and cultural knowledge to support their process of understanding Chinese country as a whole and to support their career/work. The students feel that they lack the ability to understand the literary and cultural texts. The students expect an increase in reading comprehension through various texts and contextual themes.

The observation of the learning process in the Reading $\mathrm{V}$ course shows that the process of reading comprehension is still more dominated by the lecturers than the students. The textbooks do not contain the literary and cultural texts of the Chinese language. The lecturers use the one-way method by employing more lecturing method than inviting the students to participate actively in the classroom. The students seem interested in literary and cultural topics.

Thus, the learning model design of reading contextual Chinese literary and cultural texts that is suitable for the students of the Faculty of Literature, Department of Chinese Literature is the contextual learning model. It is because the model facilitates the students' involvement in the learning process through discussion and reading practices. The statement of the feasibility of the developed learning model is obtained through the experts' review with the following results. The Chinese language teaching experts state that the teaching and learning materials of the Chinese literary and cultural texts are contextually good and worthy to be used as the teaching materials.

The Chinese literary and cultural experts state that the Chinese literary and cultural texts under contextual learning are good and feasible to be used as the reading references for the students. 


\section{References}

[1] J. Elaine, Contextual Teaching \& Learning, terj. Ibnu Seriawan. Bandung.

[2] J. D. Brown, The elements of language curriculum : A systematic approach to program development. Heinle \& Heinle Publisher, 1995.

[3] W. Gall, M.D. \& Borg, Educational Research: An Introduction. New York: Longman, 1983.

[4] Hong Yi Lee, "Inquiry-based teaching in second and foreign language pedagogy," J. Lang. Teach. Res., vol. Vol 5 No 6, no. Finland ISSN 17984769., p. pp.1236-1244, 2014.

[5] J. Munby, "Communicative Syllabus Design," Cambridge Univ. Press, no. Cambridge, 1978.

[6] R. R. Jordan, English for academic purposes: A guide and resources book for teachers. Cambridge. Cambridge University Press, 2003.

[7] M. D. Borg, R., Walter, \& Gall, Educational research: An introduction (2nd ed. New York: Longman, 1989.

[8] D. K. Firdaus Su'udiah, I Nyoman Sudana Degeng, "Pengembangan buku teks tematik berbasis Kontekstual. Jurnal Teori, Penelitian dan Pengembangan.," Hal 17441748. EISSN2502-471X, vol. Volume 1, p. No;9, 2016. 